\title{
Systematic Review of the Effectiveness of Relaxation Training for Depression
}

\author{
Carol N. S. Fung ${ }^{1, *}$, Robert White ${ }^{2}$ \\ ${ }^{1}$ Occupational Therapy Department, Tan Tock Seng Hospital, 308433, Singapore \\ ${ }^{2}$ School of Health, Community and Education Studies, Northumbria University, Newcastle, England
}

\begin{abstract}
Depression is a burdening disease worldwide despite the availability of published clinical guidelines, necessitating an expansion of treatment options. Relaxation training (RT) is an easily accessible treatment that receives limited research attention on its effectiveness for treating depression. This systematic review retrieved eight studies with mixed methods to evaluate the effectiveness of RT in treating depression using qualitative thematic analysis. Findings showed that $\mathrm{RT}$ is a simple, low-cost treatment that can alleviate self-reported mild depressive symptoms in young populations. It is a coping skill that boosts individuals' sense of self-efficacy, counteracting the effects of depression. RT plays the role of a common adjuvant treatment that is endorsed and used by practitioners, non-professional personnel, patients and the general public. With further evidence on its long-term effects and the suitable recipients, RT can be promoted which can possibly lessen the burden of depression.
\end{abstract}

Keywords Relaxation, Depression, Complementary Medicine, Mind Body Medicine

\section{Introduction}

According to World Health Organization (WHO) projections, depression, one of the most common mental disorders, will become the leading cause of global burden of disease by 2030, rising from being the third leading cause in 2004[1]. Depression interferes with affected individuals and those surrounding them, exacting a high toll on societies in terms of productivity and healthcare resources. Despite these sobering facts, effective treatments for depression are available, suggesting that this burden can be reduced.

Numerous clinical guidelines for the treatment of depression published by healthcare authorities worldwide exist and are considered as best practice in the field. However, the availability of guidelines does not equate to successful application in clinical practice. Depression presents many challenges, not least the high proportion of sufferers who do not seek medical help or go untreated. Even with treatment, many individuals fail to achieve an adequate response or subsequently relapse[2]. The WHO's projections simply reflect the truth that the problem of depression is increasing in severity despite the existence of guidelines.

The various clinical guidelines for depression are based on Western medicine. They provide similar basic principles of treatment, including individualised treatment plans, preparing the patient for potential long-term treatment, providing

* Corresponding author:

carol.fung@gmail.com (Carol N.S. Fung)

Published online at http://journal.sapub.org/ijap

Copyright (C) 2012 Scientific \& Academic Publishing. All Rights Reserved measurement-based care and treating to remission. These guidelines are evidence-based, with the greatest weight accorded to placebo-controlled double-blind trials; however, certain factors besides evidence can influence differences in specific recommendations, such as the composition of the group actually determining what should become guidelines, underlying mandates, and cultural attitudes[3]. As such, expanding treatment options beyond existing clinical guidelines and reviewing plausible treatments beyond conventional trends is crucial.

Relaxation is generally understood as the opposite of tension. Relaxation Training (RT) is defined as any technique, process or activity that helps a person to relax, to voluntarily let go of tension and attain a state of increased calmness[4]. RT originated in Western medicine but is often classified as Complementary and Alternative Medicine (CAM) nowadays because it is not practised as a mainstream treatment as frequently as before. RT has nevertheless been found to be the popular CAM used for depression[5-7]. Various relaxation techniques are available as an independent or adjuvant treatment, such as Guided Imagery (GI), Progressive Muscle Relaxation (PMR), Deep Breathing techniques (DB), autogenic training, meditation, biofeedback and hypnosis. Although evidence of RT as an effective treatment for a number of conditions such as pain, anxiety, insomnia and surgical procedures has been well-established[8,9], limited research attention has been given to treating depression with RT.

While the scope of RT can be broad, research evaluation on the effectiveness of RT must be specific. This study focuses on the more commonly used relaxation techniques of GI, PMR and DB, whether administered in combination or 
individually. RT overlaps both conventional Western medicine and CAM, although the line between the two systems is often blurred. RT plausibly possesses characteristics of both systems. For instance, while Western medicine emphasises objective and reductionist analysis, CAM gravitates towards the subjective and holistic approach. RT can also serve as good a stepping-stone for mainstream practitioners of conventional medicine to explore into the domain of CAM, or vice versa, despite differences in the qualifications of the practitioners. Nonetheless, belonging to both Western medicine and CAM or being easily accessible does not mean RT is effective for depression, necessitating an evidential basis to support this postulation.

The present study therefore aims to determine whether RT is effective in treating depression and if so, to explore ways to enhance its effectiveness.

\section{Method}

\subsection{Research Design}

This study is a systematic literature review with qualitative thematic analysis. While most systematic reviews value only improvements on validated depression scales as outcome measures, this study does not hew to a rigid definition of treatment effectiveness but allows exploration into the effectiveness defined by service users and providers in treating depression. Moreover, the qualitative approach is used to address effects according to corresponding RT techniques, instead of pooling findings from various techniques to generalize an overall effect.

This study is therefore expected to supplement the recent systematic review and meta analysis published by the Cochrane Library[10], which found that RT produced better effects than wait-listing or minimal treatment (SMD $=-0.59$ ( $95 \%$ CI -0.94 to -0.24)) for cases of self-reported depression, as well as favourable but non-significant effects for cases of clinician-rated depression. However, RT had a smaller effect for cases of self-reported depression as compared to psychological treatment (mainly Cognitive Behavioural Therapy (CBT)) (SMD = 0.38 (95\% CI 0.14 to 0.62$))$. There was no significant difference for cases of clinician-rated depression (SMD $=0.29$ (95\% CI -0.18 to 0.75$)$ ).

\subsection{Search Strategies}

The review question was deliberately broken down into the four facets of "Patients", "Intervention", "Comparison" and "Outcomes"[11], commonly abbreviated as PICO. Search strategies were piloted between April and May 2011. Modifications were made to maximise the yield of relevant articles with sensitivity favoured over specificity. Table 1 shows the summary of the search terms and inclusion criteria.

Seven electronic databases, AMED, CINAHL, the Cochrane Library, EMBASE, Ovid MEDLINE, PsycINFO and PubMed Central, were searched to retrieve English articles published from 2000 till May 2011 according to search terms in Table 1. Additional searches were made on the Internet and enquiries sent to the experts to look for grey literature or ongoing research. Articles with a score of 2.5 or above that matched the inclusion criteria were included for quality assessment.

A total of 234 articles were initially retrieved and subjected to liberal title screening. 56 articles were retained with 21 (37.5\%) repetitions across databases. Hence, 35 articles were selected for further abstract evaluation, from which 22 were excluded for the following reasons: (i) RT was not used to treat depression; (ii) RT was a part of a treatment package; (iii) the study was a prevalence survey without data on treatment effectiveness; (iv) geriatric samples were studied instead of adolescents and adults; or (v) the topics were irrelevant to the present study.

Table 1. PICO Search terms and inclusion criteria

\begin{tabular}{|c|c|c|c|c|}
\hline & PICO & Search terms & Inclusion criteria & Score \\
\hline \multirow[b]{3}{*}{ 苛 } & \multirow{3}{*}{$\begin{array}{l}\text { Adolescents or adults with } \\
\text { depression, dysthymic disorders, } \\
\text { mood disorders or affective } \\
\text { disorders }\end{array}$} & \multirow{3}{*}{$\begin{array}{l}\text { Depress* } \\
\text { OR dysthymic } \\
\text { OR mood } \\
\text { OR affective }\end{array}$} & Adolescent subjects & 0.5 \\
\hline & & & Adult subjects & 0.5 \\
\hline & & & $\begin{array}{l}\text { One of the following as primary condition without comorbidity: } \\
\text { Unipolar depressive disorder without psychotic symptoms } \\
\text { High level of depressive symptoms } \\
\text { Elevated score in depression scale }\end{array}$ & 1 \\
\hline 总 & $\begin{array}{l}\text { Relaxation training, progressive } \\
\text { muscle relaxation, guided im- } \\
\text { agery or deep breathing exer- } \\
\text { cises }\end{array}$ & $\begin{array}{l}\text { Relax* } \\
\text { OR imagery } \\
\text { OR deep breathing }\end{array}$ & \multirow{2}{*}{$\begin{array}{l}\text { Either of the following: } \\
\text { Review of effectiveness of RT or CAM with RT included } \\
\text { Quantitative or qualitative study on RT/GI/PMR that relates to } \\
\text { its effectiveness } \\
\text { Randomised Control Trial (RCT) of RT compared with } \\
\text { CBT/waitlist/no treatment }\end{array}$} & \multirow[t]{2}{*}{1} \\
\hline 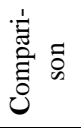 & $\begin{array}{l}\text { CAM or Mind-body medicine or } \\
\text { none }\end{array}$ & $\begin{array}{l}\text { Complementary } \\
\text { OR alternative } \\
\text { OR Mind-body }\end{array}$ & & \\
\hline 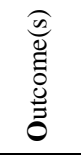 & $\begin{array}{l}\text { Reduced depressive symptoms } \\
\text { or lowered scores in depression } \\
\text { scales or subjective improve- } \\
\text { ment }\end{array}$ & & & \\
\hline
\end{tabular}


Table 2. Quality assessment

\begin{tabular}{|c|c|c|c|}
\hline & Quantitative study & Qualitative study & Score \\
\hline \multirow[b]{2}{*}{ Populations } & \multicolumn{2}{|l|}{ Representative? } & \multirow[b]{2}{*}{$2 / 1 / 0$} \\
\hline & $\begin{array}{l}\text { Adequate and appropriate sampling } \\
\text { Explicit eligibility criteria and relevant prognostic } \\
\text { characteristics }\end{array}$ & $\begin{array}{l}\text { Purposeful sampling } \\
\text { Attention to the diverse contexts that the study is aiming to } \\
\text { explore }\end{array}$ & \\
\hline \multirow[b]{2}{*}{$\begin{array}{l}\text { Intervention \& } \\
\text { Comparison }\end{array}$} & \multicolumn{2}{|l|}{ Reliable and valid? } & \multirow[b]{2}{*}{$2 / 1 / 0$} \\
\hline & $\begin{array}{l}\text { Minimised bias from allocation and treatment im- } \\
\text { plementation }\end{array}$ & $\begin{array}{l}\text { Explicit and appropriate data collection design } \\
\text { Attention to the subjective meanings given by the partici- } \\
\text { pants }\end{array}$ & \\
\hline \multirow{2}{*}{ Outcomes } & \multicolumn{2}{|l|}{$\begin{array}{l}\text { Well-measured and capable of generalisation? } \\
\text { Limitations discussed and contributions made }\end{array}$} & \multirow{2}{*}{$2 / 1 / 0$} \\
\hline & Relevant and appropriate measurement & $\begin{array}{l}\text { Explicit transition from data to interpretation and/or theo- } \\
\text { retical link }\end{array}$ & \\
\hline
\end{tabular}

Potentially relevant citations identified after theral screening of all search results ( $n=35$ )

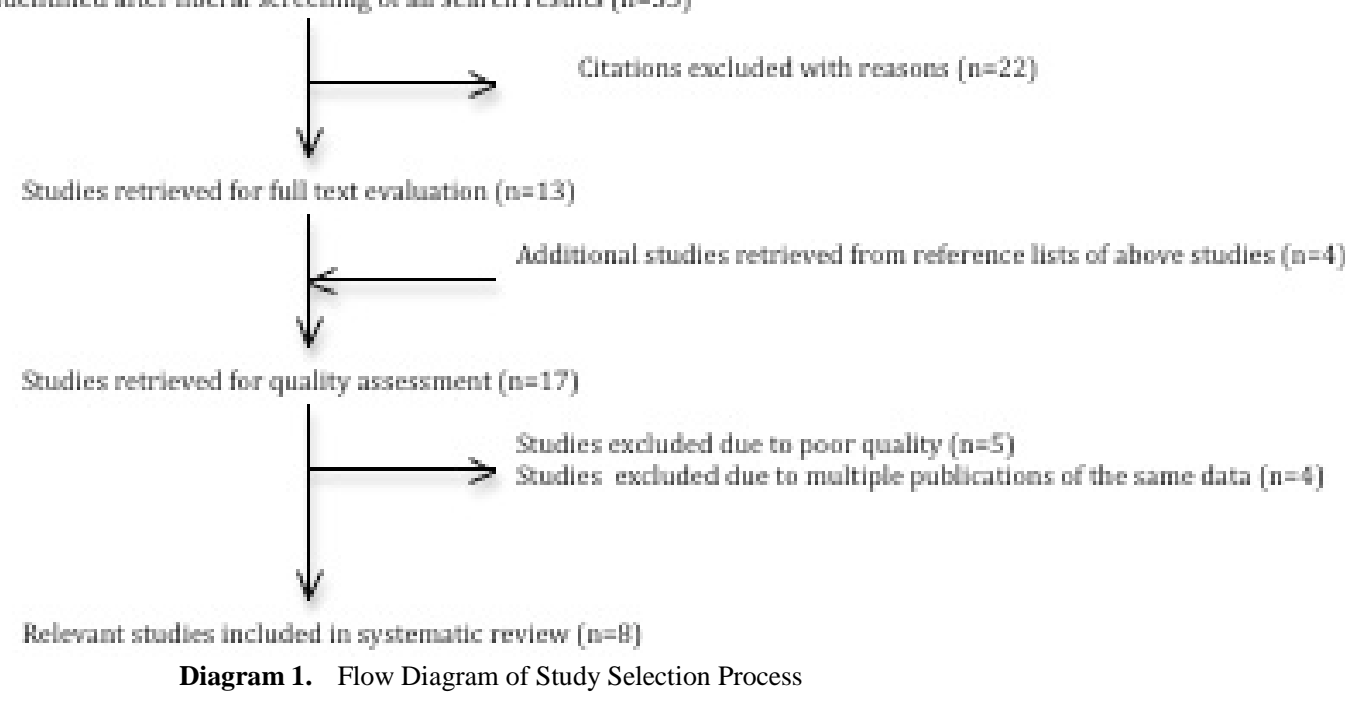

The remaining 13 articles were retrieved for full text evaluation. Another four articles from the reference lists were added into the selection process, resulting in 17 articles being subjected to quality assessment.

\subsection{Quality Assessment}

The quality assessment was derived from the same PICO framework as used for the searches and is shown in Table 2 with PICO broken into three clusters. Components required to fulfil the quality of each facet in either quantitative or qualitative studies were taken with reference to established quality assessment scales.

The scores quantified quality, with 2 being good, 1 being fair and 0 being poor. An article that scored at least 1 for each cluster (i.e. at least a total of 3 ) was included in the review. Five out of 17 studies were excluded due to low evidential value; the remaining 12 studies consisted of four reviews, three qualitative studies and five experimental trials. Among the four reviews, only the latest and most comprehensive were selected to minimise any accumulating effect on findings based on similar data. As two of the five experimental trials were multiple publications on the same research with different focus, only that with the most definitive results was selected. Ultimately, eight studies were included in the data extraction and analysis. Diagram 1 shows the summary of the selection process

\section{Results}

\subsection{Characteristics of Included Studies}

Of the eight included studies, five were experimental trials on the use of RT, two were correlational studies and the last was a systematic review with meta-analysis. All the studies, save for three experiments trials, were published from 2007 to 2010. The remaining three experimental trials were published between one to two decades ago and were retrieved from the reference lists of some of the shortlisted studies. 
They were included despite dated publication as they met both the inclusion criteria and quality standards. Moreover, there were no other reasons for excluding them.

Three of the eight studies used a general definition for RT, another three referred to PMR as RT and two used GI. As a result, during the data analysis for the present study, attention was placed on the effect of relaxation on depression and the corresponding technique used.

\subsection{Findings from Experimental Studies}

The findings from the five selected experimental studies [12-16] are shown in Table 3.

\subsubsection{Features of RT and Outcome Measures}

These studies involved a total of 166 participants who completed the prescribed treatments, which were administered by participants themselves and a wide variety of personnel such as psychologists, social workers and nurses. The reported duration of the treatment sessions ranged from 20 minutes daily to 90 minutes weekly, lasting between 10 days and 16 weeks. The treatments could be administered individually or in small groups, and could take place anywhere convenient, with minimum setting requirements. For instance, RT was administered in a school, in a clinic, in a university and at hospital bedsides, as reported in the selected studies. It appeared that treatment taking place at a convenient location coinciding with the participants' daily whereabouts resulted in higher attendance and better results. However, the selected studies showed that regardless of the location of the treatment, daily relaxation practice and generalisation across different situations were important elements.

Outcome measures from the experiments were mostly obtained prior to treatment and upon termination. There was generally a lack of long-term follow-up evaluation on the effect of RT on depression. Although a consensus on the long-term effect of RT is lacking, reference[14] found that the RT group continued to improve from depression while the CBT group had reached a plateau by the third month, resulting in very comparable results from both RT and CBT eventually at 6-month post-treatment evaluation.

The outcome measures used in the selected studies included self-reported and clinician-rated depression scales, structured or semi-structured interviews, and purposefully constructed questionnaires for the specific study. Other than those scales commonly used in research, uncommon measures were validated before implementation. Consistent with other established evidence, the selected studies also found RT to be effective in reducing anxiety. As anxiety is a common comorbidity of depression, it was suggested in three studies that improvement in depression was partially caused by reduced anxiety.

\subsubsection{Cognitive Involvement and Facilitating Factors}

Although it is clearly known that RT, especially PMR, is a non-specific treatment, there have been inconsistent as- sumptions but implicit agreement on the involvement of cognition in RT. Reference[13] intended to find out the unique effect of CBT by comparing it with RT, because of the assumption that RT lacked cognitive involvement. However, after his experiment, he concluded that RT and CBT shared certain key elements (such as building skills of mental focussing and passively ignoring distracting thoughts) and were more alike than different. Reference[14] found similar results, namely that the effects of CBT and RT were very similar by 6 months post-treatment. Specifically for GI, it was believed that GI could play a role in cognition even if people were unaware of that fact (Thomas, 1999, cited in [15]). Reference[16] highlighted that a psychodynamic approach was used in the Bonny Method of Guided Imagery and Music (BMGIM), with the cognitive process being a main characteristic of the therapy.

The above shows that cognitive involvement in the course of RT cannot be dismissed. In line with the current popularity of integrative therapy, flexibility and modification in various modalities is acceptable as long as this suits service users. Hence, RT should be understood as a behaviourally oriented treatment that also intervenes with individuals' cognition.

Although specific BMGIM was used by [16] and was considered a different form of GI, it is nonetheless a relaxation technique. A closer examination of the BMGIM protocols reveals that PMR, GI and DB were components of the therapy, but its distinctive features were the purposefully chosen classical music and the psychodynamic approach used. The findings from [16] are therefore valuable in recording the subjective experience from the perspective of RT users.

In comparison with[15], GI in this latter study was specifically designed to beautify the hospital context, which was perceived as constrictive for inpatients. Thus, the key point of GI is to idealise unfavourable situations experienced by the individuals through imagination. The positive guidance of such imagination and the facilitation towards a pivotal moment are of utmost importance. As for PMR, the emphasis on daily practice and generalisation are key facilitating factors.

\subsubsection{Potential Mechanisms}

The studies suggest a number of mechanisms by which RT works on depression; these can be categorised into physical and psychosocial pathways. First, RT can directly or indirectly enhances the production of endorphins, which have analgesic and antidepressant effects[12]. Secondly, the state of relaxation promotes a deeper level of physical, emotional and spiritual harmony, as well as stability and calmness[16]. It allows individuals to push aside the barriers of body rigidity, irritability and insecurity[16], and develop coping skills that increase the sense of self-control and self-efficacy [12-13]. Although these mechanisms of RT are not conclusive, the selected studies have demonstrated the efficacy of $\mathrm{RT}$ in the treatment of depression. 
Table 3. Findings from Experimental studies

\begin{tabular}{|c|c|c|c|c|}
\hline Study & Design & Participants & Treatment & Results \\
\hline $\begin{array}{l}\text { Reynolds \& } \\
\text { Coats, } 1986 \\
\quad[12]\end{array}$ & $\begin{array}{l}\text { RCT comparing } \\
\text { CBT, RT and } \\
\text { waitlist on ado- } \\
\text { lescents with } \\
\text { depression in the } \\
\text { U.S. }\end{array}$ & $\begin{array}{c}30 \text { students from a high school } \\
\text { screened with high self-reported } \\
\text { depressive symptoms. } \\
19 \text { (63.3\%) females; all whites, mean } \\
\text { age } 15.65 \text {. } \\
24 \text { completed post treatment assess- } \\
\text { ment, } 21 \text { completed 5-week fol- } \\
\text { low-up assessment. } \\
\text { Mean attendance was } 8.16 \text { in CBT } \\
\text { group, 8.25 in RT group. }\end{array}$ & $\begin{array}{l}\text { Jacobsen's (1938) PMR and its } \\
\text { generalisation across different situa- } \\
\text { tions were practiced. } \\
\text { The } 2^{\text {nd }} \text { author conducted ten } \\
\text { 50-minute sessions over } 5 \text { weeks of } \\
\text { small-group CBT and RT in the same } \\
\text { high school. }\end{array}$ & $\begin{array}{l}\text { Both CBT and RT produced } \\
\text { significantly reduced depres- } \\
\text { sive symptoms as compared to } \\
\text { the group in waitlist at post } \\
\text { treatment and 5-week fol- } \\
\text { low-up. } \\
\text { Differences between the } 2 \\
\text { treatment groups were } \\
\text { non-significant. }\end{array}$ \\
\hline $\begin{array}{l}\text { Murphy, } \\
\text { Carney, } \\
\text { Knesevich, } \\
\text { Wetzel \& } \\
\text { Whitworth, } \\
1995 \text { [13] }\end{array}$ & $\begin{array}{l}\text { RCT comparing } \\
\text { CBT, RT and } \\
\text { tricyclic antide- } \\
\text { pressants in } \\
\text { treatment of de- } \\
\text { pression in the } \\
\text { U.S. }\end{array}$ & $\begin{array}{c}37 \text { participants recruited through } \\
\text { news release. } \\
26 \text { (70.3\%) females; } 36 \text { (97.3\%) } \\
\text { whites. } \\
\text { Mean age } 39.4 \text { (SD 10.9). } \\
29 \text { completed } 16 \text { weeks of therapy or } \\
\text { recovered earlier. } \\
\text { Mean attendance was } 16.6 \text { in CBT } \\
\text { group; } 15 \text { in RT group; } 14.9 \text { in } \\
\text { medicine group. }\end{array}$ & $\begin{array}{l}\text { PMR* was conducted by } 3 \text { psy- } \\
\text { chologists and } 1 \text { social worker, while } \\
\text { CBT was conducted by } 3 \text { psycholo- } \\
\text { gists at the researchers' university. } \\
\text { Homework of listening to a relaxa- } \\
\text { tion tape for } 20 \text { minutes daily was } \\
\text { prescribed in RT group. } \\
\text { For both treatments: individual basis; } \\
50 \text { minutes per session; } 1-2 \text { visits } \\
\text { weekly for the first month and a } \\
\text { weekly visit thereafter, up to a } \\
\text { maximum of } 20 \text {. }\end{array}$ & $\begin{array}{l}\text { Both CBT and RT showed } \\
\text { efficacy in treatment for milder } \\
\text { depression at post treatment. No } \\
\text { further follow-up assessment } \\
\text { was conducted. } \\
\text { Dropouts were significantly } \\
\text { more depressed before treat- } \\
\text { ment than other participants. }\end{array}$ \\
\hline $\begin{array}{l}\text { Wood, Har- } \\
\text { rington \& } \\
\text { Moore, } 1996 \\
\quad[14]\end{array}$ & $\begin{array}{l}\text { RCT comparing } \\
\text { CBT and RT in } \\
\text { adolescents with } \\
\text { depression in the } \\
\text { U.K. }\end{array}$ & $\begin{array}{l}\text { Doctors referred } 53 \text { adolescent }(9- \\
17 \text { years old) outpatients attending } \\
\text { depression specialist clinics. } 48 \\
\text { completed the therapy. } \\
24 \text { in CBT group (67\% female, mean } \\
\text { age 13.8); } 24 \text { in RT group ( } 71 \% \\
\text { female, mean age } 14.6) \\
\text { Mean attendance was } 6.4 \text { in CBT } \\
\text { group, } 6.2 \text { in RT group. }\end{array}$ & $\begin{array}{l}\text { PMR* was conducted by two main }^{*} \\
\text { authors in } 5 \text { to } 8 \text { sessions on indi- } \\
\text { vidual basis at the specialist clinic. }\end{array}$ & $\begin{array}{l}\text { Improvements in CBT group } \\
\text { were significantly better than in } \\
\text { RT group at post treatment. } \\
\text { Differences between the two } \\
\text { groups reduced by the third } \\
\text { month follow-up. By } 6 \text { months, } \\
\text { the differences were trivial. }\end{array}$ \\
\hline $\begin{array}{l}\text { Apostolo \& } \\
\text { Kolcaba, } \\
2009 \text { [15] }\end{array}$ & $\begin{array}{l}\text { Quasi-experiment } \\
\text { on the effects of } \\
\text { GI on comfort, } \\
\text { anxiety, and stress } \\
\text { of psychiatric } \\
\text { in-patients with } \\
\text { depressive disor- } \\
\text { ders in Portugal. }\end{array}$ & $\begin{array}{c}60 \text { short-term hospitalised depressive } \\
\text { patients selected by convenient sam- } \\
\text { pling. } \\
30 \text { in GI group with } 20 \text { (66.7\%) } \\
\text { females and mean age at } 39.57 . \\
30 \text { in Treatment as Usual (TAU) } \\
\text { group with } 20 \text { (66.7\%) females and } \\
\text { mean age at } 41.2 \text {. } \\
\text { All completed therapy with full } \\
\text { attendance. }\end{array}$ & $\begin{array}{l}\text { Participants listened to a 21-minute } \\
\text { long audio taped CD individually } \\
\text { once a day for } 10 \text { days during the } \\
\text { period of hospitalisation. } \\
\text { The CD contained soothing music } \\
\text { and instructions on (1) DB, (2) PMR, } \\
\text { (3) natural images imagination, (4) } \\
\text { positive and serene images of the } \\
\text { hospital context. }\end{array}$ & $\begin{array}{l}\text { GI group showed significant } \\
\text { lower depression, anxiety and } \\
\text { stress as well as higher comfort } \\
\text { than TAU group at post treat- } \\
\text { ment. }\end{array}$ \\
\hline $\begin{array}{l}\text { Lin, Hsu, } \\
\text { Chang, Hsu, } \\
\text { Chou \& } \\
\text { Crawford, } \\
2010[16]\end{array}$ & $\begin{array}{l}\text { Non-controlled } \\
\text { and discov- } \\
\text { ery-oriented } \\
\text { quasi-experiment } \\
\text { on the pivotal } \\
\text { moments and } \\
\text { changes experi- } \\
\text { enced by depres- } \\
\text { sive patients dur- } \\
\text { ing GI in Taiwan. }\end{array}$ & $\begin{array}{l}9 \text { patients were recruited from an } \\
\text { outpatient clinic through physicians' } \\
\text { referral and direct advertisement. } \\
5 \text { completed the treatment with } 4 \\
\text { (80\%) of them females, age range } \\
\text { from } 30 \text { to } 42 \text { years, and all were } \\
\text { taking antidepressants for } 2-5 \text { years. }\end{array}$ & $\begin{array}{l}\text { A specialist conducted a specific } \\
\text { kind of GI called Bonny Method of } \\
\text { Guided Imagery and Music } \\
\text { (BMGIM). } \\
8 \text { sessions of BMGIM lasting } 90 \\
\text { minutes long were conducted weekly } \\
\text { at a music therapy laboratory in a } \\
\text { university. } \\
\text { The main author interviewed par- } \\
\text { ticipants individually by phone for } \\
\text { their experiences and feelings of the } \\
\text { sessions. }\end{array}$ & $\begin{array}{l}3 \text { main themes were discovered } \\
\text { during the process of BMGIM: } \\
\text { Pushing aside the barriers } \\
\text { (Moments of releasing } \\
\text { min-body rigidity); } \\
\text { Gaining new insights (Moments } \\
\text { of awareness and inspiration); } \\
\text { and } \\
\text { Moving forward (Moments of } \\
\text { acceptance and inner transfor- } \\
\text { mation). }\end{array}$ \\
\hline
\end{tabular}

* PMR based on the programme of Bernstein and Borkevec (1973)

\subsection{Findings from Non-Experimental Studies}

Although the focus and methodology of the three studies [10,17-18] differ as shown in Table 4, they provide certain qualitative data that helps to understand the effect of RT on depression.

First, there is a common belief among various clinical professionals, young people and parents that RT can be useful for depression. Secondly, RT is a simple treatment that can be administered at minimal cost, from the perspective of both service providers and users. RT can also be readily formatted into a manual and requires only brief training.

Reference[10] suggested that RT has the potential to be used as a first-line psychological treatment for depression. Those who did not respond to RT within a set time could be 
offered more complex psychological treatment such as CBT. However, it is still a fact that RT cannot be found in any of the established clinical guidelines. Reference[17] reported that the main barriers encountered by clinicians included limited knowledge of the Mind-body techniques and concern that patients would feel their symptoms were being discounted. They also proposed that a concerted effort be made on the part of residence training programmes for MBM methods to be seriously studied and incorporated into medical practice. While MBM is not a typical subject in the formal training of Family Medicine and Psychiatry, the faculty and residents surveyed showed interest in learning about this, including RT.

Regardless of whatever consensus and differences exist between the providers and users of mental health services, it is ultimately the users' choice to receive a treatment and their perception of the treatment that matters. All three studies encouraged further research attention to be invested in this simple and easily acceptable psychological treatment.

\subsubsection{Synthesis of All Findings}

Putting all the findings together, three main themes on the effectiveness of RT on depression can be discerned.

Theme 1: RT can produce immediate effects of brief duration to relieve self-reported depressive symptoms in younger populations and populations with milder forms of depression.

The selected experimental trials showed that RT produced improvement in cases of self-reported depressive symptoms at post-treatment evaluation. In fact, in trials where RT was used as a control treatment, the effects of RT surprised some researchers by producing effects comparable to those obtained by using the more reputable treatment of CBT. Although [14] reported that the RT group continued to improve up to six months post-treatment, the long-term effects of RT are inconclusive. The illustration by [13] of personal attention as a dose-response curve possibly supplements the reason for more immediate effect over the long-term effects. They suggested a saturable system of personal attention: if a little is good, more is better, but only up to a point. However, due to the lack of long-term follow up in the studies, neither the saturation point nor the long-term effects of RT can be defined.

Table 4. Findings from Non-Experimental studies

\begin{tabular}{|c|c|c|c|c|}
\hline \begin{tabular}{|l|} 
Study \\
\end{tabular} & Design & Samples & Methods & Results \\
\hline \begin{tabular}{|l|} 
Sierpina, \\
Levine, \\
Astin \& Tan, \\
2007 [17]
\end{tabular} & $\begin{array}{l}\text { Correlational study on } \\
\text { the attitudes, barriers } \\
\text { and gender difference in } \\
\text { the use of Mind-body } \\
\text { Medicine (MBM) } \\
\text { among the faculty and } \\
\text { residents in Psychiatry } \\
\text { and Family Medicine. }\end{array}$ & $\begin{array}{l}74 \text { physicians from the Univer- } \\
\text { sity of Texas Medical Branch } \\
\text { completed the survey. } \\
\text { Response rate was } 69 \% \text {. } \\
51.4 \% \text { aged } 26 \text { to } 39 ; 50 \% \\
\text { females. } \\
50 \% \text { residents, } 43 \text { (58.1\%) from } \\
\text { Family Medicine, } 31 \text { (41.9\%) } \\
\text { from Psychiatry. }\end{array}$ & $\begin{array}{l}\text { Web-based survey on the use of } \\
\text { MBM was derived from a longer } \\
\text { version used at the national level. It } \\
\text { was piloted and approved before } \\
\text { implementation. } \\
\text { Surveys were sent out over } 6 \text { weeks. } \\
\text { All data was directly imported into a } \\
\text { database, which kept the subjects } \\
\text { anonymous. Statistical analysis was } \\
\text { employed to interpret findings. }\end{array}$ & $\begin{array}{l}\text { A primary facilitator of MBM use in } \\
\text { clinical practice was personal knowl- } \\
\text { edge of and experience with these } \\
\text { therapies. } \\
\text { Females showed significantly higher } \\
\text { usage of MBM. } \\
\text { Both groups of physicians viewed } \\
\text { MBM as useful in depression, and } \\
\text { used it to a similar degree, but family } \\
\text { physicians perceived greater barriers } \\
\text { to usage than psychiatrists. }\end{array}$ \\
\hline \begin{tabular}{|l|} 
Jorm, Mor- \\
gan \& \\
Wright 2008 \\
{$[18]$}
\end{tabular} & $\begin{array}{l}\text { Correlational study on } \\
\text { the perceived usefulness } \\
\text { on intervention for } \\
\text { depression in young } \\
\text { people in Australia. }\end{array}$ & $\begin{array}{l}\text { Clinician samples consisted of: } \\
436 \text { psychiatrists; } 365 \text { GPs; } \\
553 \text { psychologists; and } \\
416 \text { mental health nurses. } \\
\text { Response rates were: } \\
34.8 \% \text { (psychiatrists); 24.9\% } \\
\text { (GPs); } \\
40.3 \% \text { (psychologists); and } \\
34.3 \% \text { (mental health nurses). } \\
\text { Youth and parent samples } \\
\text { consisted of: } \\
2778 \text { youth aged 12-25; } \\
1474 \text { co-resident parents. } \\
\text { Response rates were: } \\
61.5 \% \text { (youth); and 68.5\% } \\
\text { (parents). }\end{array}$ & $\begin{array}{l}\text { A survey that consisted of a vignette } \\
\text { of a young person with a mental } \\
\text { disorder, and questions to participants } \\
\text { to assess their recognition of the } \\
\text { disorder in the vignette, beliefs about } \\
\text { first aid, treatment and prevention. } \\
\text { Surveys were sent to the clinician } \\
\text { samples by post and completed } \\
\text { anonymously. } \\
\text { The same surveys were conducted by } \\
\text { phone a year earlier (in 2006) on a } \\
\text { national sample of youth and } \\
\text { co-residents parents. } \\
\text { Statistical analysis was employed to } \\
\text { interpret findings. }\end{array}$ & $\begin{array}{l}\text { Clinicians generally have many } \\
\text { consensuses across their beliefs on the } \\
\text { use of MBM. } \\
\text { Compared to clinicians, youth and } \\
\text { parents gave lower ratings to CBT and } \\
\text { antidepressants, but higher ratings to } \\
\text { close friends and family. } \\
\text { The one intervention endorsed by } \\
\text { clinicians, youths and parents, but not } \\
\text { mentioned by clinical practice guide- } \\
\text { lines, was RT. } \\
\text { Generic terms like counselling was } \\
\text { seen more positively in youth and } \\
\text { parents compared to the clinicians. }\end{array}$ \\
\hline $\begin{array}{l}\text { Jorm et al, } \\
2009 \text { [10] }\end{array}$ & $\begin{array}{l}\text { Systematic Review on } \\
\text { Relaxation for depres- } \\
\text { sion by the Cochrane } \\
\text { Collaboration. }\end{array}$ & $\begin{array}{l}\text { All published or unpublished } \\
\text { RCTs or quasi-RCTs evaluating } \\
\text { RT on treating depression were } \\
\text { reviewed without restrictions in } \\
\text { time, language. }\end{array}$ & $\begin{array}{l}15 \text { trials with } 11 \text { included in the meta } \\
\text { analysis. } \\
\text { Analysis was categorised into com- } \\
\text { parison with (1) waitlist, no treat- } \\
\text { ment, or minimal treatment; (2) } \\
\text { psychological treatment; (3) com- } \\
\text { plementary and lifestyle treatments; } \\
\text { (4) medication; and (5) the effects of } \\
\text { RT combined with medication. }\end{array}$ & $\begin{array}{l}\text { RT was more effective at reducing } \\
\text { self-rated depressive symptoms than } \\
\text { no or minimal treatment, but not as } \\
\text { effective as psychological treatment. } \\
\text { Data on clinician-rated depressive } \\
\text { symptoms were less conclusive. }\end{array}$ \\
\hline
\end{tabular}


Moreover, the populations studied were mainly of younger people and those with mild depression, due to the sampling design of the experiments (e.g. sampling in a high school, or using self-reported depression scales as screening criteria) as well as the fact that the more severely depressed participants dropped out of the studies[13]. Hence, a definitive finding on the effect of RT on more severe depression is lacking. Reference[16] mentioned that caution should be taken when applying BMGIM to suicidal individuals because the treatment offered both an outlet for their innermost feelings and emotions as well as an opportunity to revisit painful or negative events. One participant in that study reported being irritable and having problems in sleeping because the treatment reminded him of a revolting experience. Although[16] explained that awareness of the unwanted feelings is necessary prior to being able to move forward, caution should be taken as the process may trigger anger and fear in some.

Theme 2: RT is a simple, low-cost treatment endorsed among service users and providers.

While a qualified specialist was required to implement BMGIM, personnel with or without special qualifications carried out other types of RT. For instance, reference[14] employed a psychiatrist to manage the antidepressant group, psychologists for the CBT group, and psychologists and social workers for the RT group. In the case of[15], participants were given an audio CD to self-administer the treatment. It is clear that the manpower requirements to implement RT are comparatively less stringent. Since Edmund Jacobsen pioneered PMR in the 1930's, the format of PMR has developed in a highly systematic way with detailed step-by-step instructions on how specific muscle groups are sequentially contracted and relaxed, and how such contraction and relaxation should be synchronised with inhalation and exhalation; the manner in which therapists deal with participants is also scripted in detail. The treatment is direct and the aim straightforward. The simplicity of RT facilitates the usage of such a technique by individuals who prefer generic and simple treatment as compared to the high cost of other psychological treatments or the side effects of antidepressants.

Theme 3: RT is a vehicle for reaching a state of increased calmness by ignoring distracting thoughts. It is a coping skill that equips individual with a greater sense of self-control and self-efficacy.

$\mathrm{RT}$, regardless of any specific technique, is a treatment process with the state of relaxation as its objective. Summing up the findings from the selected studies, the state of relaxation is where the individual feels relaxed, secure, peaceful and hopeful; this is the environment where positive transpersonal change can occur. In fact, [16] reported ambivalence or lack of motivation was the principal obstacles to be overcome in triggering change. Like the citation of Bandura (1977)'s self-efficacy model in [12], psychological procedures, whatever their form, alter the level and strength of self-efficacy. Therefore, once an individual is willing to act against the depressed mood, this willingness, complemented with a supportive therapist as well as a nurturing and soothing environment, is likely to result in positive change. In other words, RT is a coping skill that equips individuals with a greater sense of self-control and self-efficacy to create positive change. Even so, it is noteworthy to bear in mind that daily relaxation practice and generalisation across situations could possibly facilitate the effectiveness of PMR, while positive guidance and facilitation towards a pivotal moment appear to facilitate GI according to the selected experimental studies. As suggested by the Cochrane review, RT has the potential to serve as a first-line psychological treatment for depression. It is indeed a vehicle for reaching the state of calmness that awakes the "authentic" mind and ignores the distracting thoughts.

\section{Discussion}

\subsection{Limitations}

In the present study, the overall assessment of the effectiveness of RT was based on only eight studies and possibly tends towards being less than fully comprehensive. As such, the inclusion criteria can be expanded so as to capture studies in languages other than English, studies conducted prior to the year 2000, RCTs that compare RT with other treatments or studies with RT used as a part of a treatment package, etc. Moreover, the operational definition of RT in the present study includes only PMR, GI and DB, although DB is actually incorporated in PMR and GI. This operational definition can be expanded to include treatments such as autogenic training, meditation, biofeedback and hypnosis in order to gather a bigger pool of articles for the review.

Quality assessment was designed to give three general grades, as in 'good', 'fair' and 'poor'. While some specifications were required in each facet of the potential research, articles with only a fair level of evidential quality would still be tolerated. In striking a balance between having a more stringent quality assessment and ensuring a decent number of articles for review, the former had to be relaxed somewhat in order to avoid a situation where there would be too few articles meeting the prescribed standards.

Among the selected studies, none considered the adverse effects of RT except [16], where there was a reminder to use caution in applying BMGIM to suicidal individuals. While a treatment with no adverse effect is a proposition too good to be true, this is possibly due to the methodology of the selected studies; a majority of the selected studies used a quantitative approach and only one quasi-experiment [16] used a qualitative approach to obtain the participants' feedback after RT. It would therefore have been difficult to capture enough qualitative data to draw conclusions about the effectiveness of RT from the personal accounts of the participants.

\subsection{Implications}

In the course of depression, the most prominent problems faced by individuals include depressed mood, the inability to 
feel pleasure, the lack of motivation and social withdrawal. RT is often used as an adjuvant treatment within other schools of psychotherapies. Although it is neither a school of thought by itself or a recommended treatment in any published clinical guidelines, RT is perceived as a helpful treatment for depression among some people, or at least some of the participants in the selected studies. Given the current and potential worldwide burden attributed to depression, the call for a more diversified and open view towards solutions to the problem is needed.

As RT is situated in the overlap between the fields of Western medicine and CAM, RT plays the role of a common adjuvant treatment used with other sophisticated therapy, a simple stress-relief modality for self-administration, or a technique taught informally by non-professional personnel. Hence, RT is considered as a versatile treatment that can be readily adapted to achieve its aim, which is to relax the individual subject to it. Besides, while few treatments can claim to belong to both conventional and unconventional systems of medicine, RT is seen as plausibly possessing characteristics of both.

RT could well have been popular in the mid $19^{\text {th }}$ century after the extensive experiments into PMR and relaxation response by Edmund Jacobsen and Herbert Benson respectively. But if so, its popularity did not last or lead to widespread acceptance as compared to other treatments preferred by mental health authorities. This phenomenon is probably due to the fact that RT is non-specific and its mechanism is unclear; without being able to explain the aetiology of the distress, RT remains a down-to-earth and straightforward treatment. It is not a core subject taught in medical schools or a treatment regularly administered by physicians. Nonetheless, from the point of view of diversification, while some people believe in sophisticated established treatments or novel high-technology treatments, others might prefer the simplicity and clarity that RT possesses. Such personal preference for one does not invalidate the other.

The experimental studies showed that RT can produce immediate effects of brief duration to relieve depression. It is important to take note of the conditions under which this evidence was obtained, namely, from cases involving self-reported symptoms, younger populations and milder forms of depression. These conditions bear resemblance to, and may be representative of, the student population and the population of young adults who are stressed with, or whose conditions are triggered by, education or work-related demands and who claim they are exhibiting depressive symptoms. Individuals from these populations may be more receptive to RT in the early onset of depression, although further research is needed to identify and confirm which population groups can best benefit from RT.

Since RT is a simple, low-cost treatment capable of bringing about cognitive, physical and psychosocial uplift to relieve the feeling of depression, RT is an ideal candidate for a basic coping skill that can be taught to students in schools and new staff in workplaces. As the application of RT can be clearly written in manuals, trainers require only brief training.
Alternatively, RT can be prescribed in pre-recorded materials, allowing the promotion of such treatment to be done readily without qualified professionals. The central idea is to generalise the acceptance and usage of such a coping skill among the target population so as to build a protective element into this population. This may help readily as and when there is a tendency that an individual may develop depression or experience a mild form of depression, thus allowing the problem to receive more immediate attention and also potentially freeing up scarce professional resources. Moreover, general public education about the idea of relaxation may raise the overall awareness of mental health.

As gleaned from the selected studies, RT, while allowing people to calm down voluntarily, also builds the skills of mental focussing and coping, resulting in an enhanced feeling of self-control or an optimal platform for professional help to build on. Given the level of effectiveness and its affordability, it is worthwhile to encourage the use of RT in a variety of settings and situations. However, as mentioned repeatedly in the selected studies, more research attention should be placed on RT since the presence of evidential support is the way that a treatment gets recognition. Future research can take the form of longitudinal studies that evaluate the long-term effects of RT, qualitative studies that interpret the experiences of people who use RT, or analyses of the cost-effectiveness of RT compared with other psychotherapies.

\section{Conclusions}

Given the severity of depression and its projected burden on the world by 2030, it is preferable to have a variety of treatment options available in addition to the existing established clinical guidelines. This study covered eight mixed studies evaluating the effectiveness of RT for the treatment of depression. The mixed methodology of the study facilitated the retrieval of relevant evidence to determine this. Tailoring the quality assessment using the PICO framework has effectively ensured adequate quality at various facets of the review question. The findings show that RT is an easily administered and low-cost treatment that can produce immediate effects to relieve self-reported depressive symptoms in younger populations and populations with milder forms of depression.

The factors that appear to facilitate the effectiveness of treatment are daily relaxation practice and generalisation across different situations for PMR and, in the case of GI, positively guided imagination and facilitation towards a pivotal moment. RT is not only a common adjuvant treatment used in other sophisticated psychotherapies by qualified professionals but is also a popular and easily accessible technique in CAM that can be administered by non- professional personnel or the individuals themselves. Although the mechanism of how RT works on depression is not precisely understood, it is generally seen as a coping skill that equips individuals with a greater sense of self-control and 
self-efficacy, thus counteracting the effects of depression.

As a result, RT has been found to be an effective treatment capable of alleviating mild self-reported depressive symptoms. However, further research is still need to consolidate the suitable populations groups for RT, the mechanisms of $\mathrm{RT}$ and to establish the long-term effects of RT. With more definitive evidence, the use of RT can be promoted so that it may eventually help to equip suitable recipients with a protective skill that can possibly lessen the burden of depression, thereby allowing for earlier intervention and the conservation of scarce professional resources.

\section{REFERENCES}

[1] Online Available: http://www.who.int/healthinfo/global_bur den_disease/GBD_report_2004update_full.pdf.

[2] Andrews, G., Sanderson, K., Slade, T. and Issakidis, G., "Why Does The Burden Of Disease Persist? Relating The Burden Of Anxiety And Depression To Effectiveness Of Treatment”, Bulletin of the World Health Organization, vol. 78, pp.446-454, 2000.

[3] Online Available: http://www.ncbi.nlm.nih.gov/pubmed/203 71031

[4] Jorm, A.F., Christensen, H., Griffiths, K.M. and Rodgers, B., "Effectiveness Of Complementary And Self-Help Treatments For Depression”, Medical Journal of Australia, vol.176, pp.S84-96, 2002.

[5] Pilkington, K.S., Rampes, H. and Richardson, J., “Complementary Medicine For Depression”, Expert Review of Neurotherapeutics, vol. 6, no.11, 1741-1751, 2006.

[6] Barnes, P.M., Bloom, B. and Nahin, R.L., U.S. Department of Health and Human Services, National Center for Health Statistics, "Complementary And Alternative Medicine Use Among Adults And Children: United States, 2007”, (DHHS Publication No. (PHS) 2009-1250). Hyattsville, MD: Centers for Disease Control and Prevention, 2008.

[7] Bertisch, S.M., Wee, C.C., Phillips, R.S. and McCarthy, E.P., "Alternative Mind-Body Therapies Used By Adults With Medical Conditions”, Journal of Psychosomatic Research, vol.66, pp.511-519, 2009.
[8] DeMarco-Sinatra, J., "Relaxation Training As A Holistic Nursing Intervention”, Holistic Nursing Practice, vol.14, no.3, pp.30-39, 2000.

[9] Online Available:http://surgery.med.nyu.edu/content?Chunk IID=37435.

[10] Jorm, A.F., Morgan, A.J. and Hetrick, S.E., "Relaxation For Depression (Review)”, Cochrane Database of Systematic Reviews, Issue 4: Art. No.: CD007142, 2009.

[11] Online Available:http://www.nlm.nih.gov/archive/20060905 /nichsr/ehta/chapter2.html

[12] Reynolds, W.M. and Coats, K.I., “A Comparison Of Cognitive-Behavioural Therapy And Relaxation Training For The Treatment Of Depression In Adolescents”, Journal of Consulting and Clinical Psychology, vol.54, no.5, pp.653-660, 1986.

[13] Murphy, G.E., Carney, R.M., Knesevich, M.A., Wetzel, R.D. and Whitworth, P., "Cognitive Behaviour Therapy, Relaxation Training, And Tricyclic Antidepressant Medication In The Treatment Of Depression”. Psychological Reports, vol.77, pp.403-420, 1995.

[14] Wood, A., Harrington, R. and Moore, A., "Controlled Trial Of A Brief Cognitive-Behavioural Intervention In Adolescent Patients With Depressive Disorders”, Journal of Child Psychology and Psychiatry, vol.37, no.6, pp.737-746, 1996.

[15] Apostolo, J.L. A. and Kolcaba, K., "The Effects Of Guided Imagery On Comfort, Depression, Anxiety, And Stress Of Psychiatric Inpatients With Depressive Disorders”, Archives of Psychiatric Nursing, vol.23, no.6, pp.403-411, 2009.

[16] Lin, M.F., Hsu, M.C., Chang, H.J., Hsu, Y.Y., Chou, M.H. and Crawford, P., "Pivotal Moments And Changes In The Bonny Method of Guided Imagery And Music For Patients With Depression”, Journal of Clinical Nursing, vol.19, pp.1139-1148, 2010.

[17] Sierpina, V., Levine, R., Astin, J. and Tan, A., "Use Of Mind-Body Therapies In Psychiatry And Family Medicine Faculty And Residents: Attitudes, Barriers, And Gender Differences”, Explore, vol.3, no.2, pp.129-135, 2007.

[18] Jorm, A.F., Morgan, A.J. and Wright, A., "Interventions That Are Helpful For Depression And Anxiety In Young People: A Comparison Of Clinicians' Beliefs With Those Of Youth And Their Parents”, Journal of Affective Disorders, vol.111, pp.227-234, 2008. 